\title{
Comentario a la Parte I de Apariencia y realidad en el pensamiento griego, de Marcelo Boeri
}

\author{
NÉSTOR LUIS CORDERO \\ Universidad de Rennes 1 \\ cordero@univ-rennes1.fr
}

\begin{abstract}
Resumen: Las nociones de "apariencia" y "realidad" que forman parte del título del trabajo de Boeri son el recurso que permite al autor hacer una verdadera radiografía de esa manera de pensar a la que abusivamente llamamos "filosofía griega", que sabe que vivimos en un mundo que podría ser mejor, lo cual supone que toda persona que quiere que "le vaya bien" en la vida debe aspirar a ciertos ideales. Esta perspectiva eminentemente ética preside la sección consagrada al socratismo y a Platón. Y, quizá sin que el autor se lo haya propuesto, se deduce de su análisis la necesidad de debilitar, e incluso suprimir, la tan comentada "separación" (khôrismós) entre lo inteligible y lo sensible, entre epistéme y aísthesis. Un análisis más detallado del Sofista de Platón habría podido enriquecer su tesis.
\end{abstract}

Palabras clave: ideales, ética, separación (khôrismós), el Sofista de Platón

\begin{abstract}
The concepts of "appearance" and "reality" (in the title of the book) is a safe-conduct permitting the author to carry out a true X-ray analysis of a thought — that we commonly call "Greek philosophy" — which acknowledges that we live in a world that could be better, which assumes that anyone who wants to improve his life must aspire to certain ideals. This eminently ethical perspective appears in the section about Socratism and Plato. And perhaps unwillingly the author states the necessity to weaken, and even suppress, the so commented "separation" (khôrismós) between the intelligible and the sensible word, between epistéme and aísthesis. A detailed analysis of Plato's Sophist would enrich Boeri's thesis.
\end{abstract}

Key words: ideals, ethics, separation (khôrismós), Plato's Sophist

Marcelo Boeri enriquece los estudios clásicos con un trabajo ejemplar, paradigmático, ya que rara vez se encuentran reunidos en una sola obra los tres pilares que confieren solidez definitiva a un ensayo sobre el pensamiento griego: erudición, originalidad y, a mi entender, provocación. A la erudición — como se debe- no se la ve, pero se la respira en cada párrafo. La originalidad se deduce ya del extenso subtítulo, como si Boeri quisiera alertar al lector, ya desde la carátula del libro, que no se imagine que va a encontrar en las espesas trescientas y pico de páginas un ensayo más sobre, justamente, "apariencia y realidad". Ambas nociones las utiliza Boeri como un trampolín que le permite 
sumergirse directamente en una verdadera radiografía de una manera de pensar —eso que abusivamente llamamos "filosofía griega" - que sabe que vivimos en un mundo - ¿aparente?- que podría ser mejor, lo cual supone que hay algo mejor - i"real"? - a lo cual debe aspirar todo aquel que quiere que "le vaya bien" en la vida (traducción sutilísima del clásico eu práttein). ¿Y la provocación? Este humilde lector no pretende comprometer al respetable autor, pero de la sección del ensayo que tendré el placer de comentar brevemente, consagrada al socratismo y a Platón, se deduce que Boeri quisiera debilitar, e incluso suprimir, el tan criticado khôrismós, lo cual —a mi parecer- si es una provocación, es más que saludable.

La sección del libro consagrada al socratismo y a Platón está estructurada, e incluso determinada, por el tratamiento de la cuestión del conocimiento. Boeri, sutil conocedor del Teeteto (y magnífico traductor: la suya es sin lugar a dudas la mejor traducción de la obra, y no sólo al español), ${ }^{1}$ encuentra en este diálogo, que está abusivamente presente en esta sección, una clave interpretativa —al menos, así lo percibe el lector-que le permite llegar al centro de la cuestión: tanto Sócrates como Platón quisieron explicarse en qué consiste conocer, lo cual los llevó a interrogarse sobre el "contenido" del conocimiento. ¿Lo que se percibe? ¿Lo que se piensa? ¿Lo que se percibe y, ergo, se piensa? ¿Lo que se piensa y que, quizá, se origina en lo que se percibe?

El Teeteto, en este sentido, es un diálogo ideal, ya que reúne (a) un análisis lúcido del fenomenismo de Protágoras —que el Sócrates platónico describe en algunos pasajes sin ocultar su admiración-; (b) un regreso al Sócrates aporético que Platón asume como propio, ya que el problema central del diálogo queda sin respuesta (¿qué es la epistémê? Vaya uno a saber...) ${ }^{2}$ y (c) un deseo de volver a las Formas, ausentes en el diálogo, pero "rejuvenecidas", deseo que se hará efectivo en el Sofista.

Hicimos ya alusión al extenso subtítulo del trabajo de Boeri. A nuestro juicio, si hay un término que privilegiar en este grupo, éste es el de "ética". En efecto: bajo la máscara de "apariencia y realidad", Boeri nos ofrece un apasionante ensayo de "ética del conocimiento", al menos en la sección que nos ocupa. El estudio de los criterios socráticos para distinguir entre el bien real y el bien aparente conduce a Boeri (después de un minucioso análisis de la cuestión del carácter involuntario del error)

\footnotetext{
${ }^{1}$ Platón, Teeteto, introducción, traducción y notas M. Boeri, Buenos Aires, Losada, 2006.

2 "No creer saber lo que en realidad no sabemos (Teet. 210c3-4) [...], sugiero, es lo que Platón entiende por 'conocimiento' en el Teet." (Boeri, op. cit., p. 138).
} 
al tema que profundizará luego en Platón, y que es quizá el rasgo más original de su análisis: el estudio del estado de ánimo y de la disposición del carácter del agente cognoscente; sólo quienes tienen estabilidad y tranquilidad de ánimo sabrán que lo aparentemente bueno puede no coincidir con lo bueno.

Siguiendo una línea coherente, el capítulo consagrado a Platón comienza con el estudio de la relación entre la Idea del Bien y la distinción que hay entre apariencia y realidad, especialmente en el caso de la justicia. Fiel al privilegio que otorga al planteamiento ético, Boeri deduce que, en este ámbito, Platón no es ni consecuencialista (suerte de utilitarista) ni deontologista, y concluye que más importante que el conocimiento de la Forma que se va a seguir es el carácter de quien es capaz de aplicarla con inteligencia. Va de suyo que Boeri es consciente del aparente círculo vicioso en que podría caerse, ya que para aplicar con inteligencia la Forma, hay que conocerla. Pero el círculo vicioso no es tal, ya que la captación de la Forma depende ya de la "disposición" anímica del agente, lo cual constituye la originalidad del enfoque de Boeri.

En efecto, a medida que se avanza en la lectura de esta sección, el lector comprende que cada uno de los capítulos que la integran aportan materiales que permitirán construir el sólido edificio que Boeri llama precisamente "un enfoque disposicional de la epistemología platónica". Se trata de "la transformación del alma individual en un estado disposicional, condición (héxis) que permite a la persona tomar distancia de sí misma y examinar su propio estado de creencia respecto de lo que cree tener conocimiento" (p. 118). No tememos a equivocarnos si afirmamos que este punto central de la posición de Boeri, así como las etapas precedentes, confieren al conocimiento (o al "saber": epistémê) un papel activo (acabamos de mencionar la noción de "transformación"), lo cual supone en más de una ocasión la colaboración entre epistémê y aísthêsis, pareja contrastada especialmente en la República, pero reunida en función de un fin común en otros diálogos, especialmente en el Teeteto.

$\mathrm{Si}$ esto es así, el único reproche que nos atreveríamos a hacer al monumental trabajo de Boeri es su uso restringido del diálogo que, curiosamente, le hubiese ofrecido elementos de peso para justificar su posición: el Sofista. En efecto, ya señalamos que incluso en una lectura superficial de Apariencia y realidad se percibe la relativización — sin llegar por ello a la negación- de la clásica noción de khôrismós, que ocupa un lugar de preferencia en lecturas superficiales de Platón. Y bien: la frase del Sofista que otorga realidad real (óntôs einai) a todo aquello que sea susceptible de actuar o de padecer (247e) relativiza 
toda posible "separación": lo individual-sensible es realmente real, ya que no sólo actúa o padece, sino que, además, al ser copia de un modelo, fue objeto de una elaboración, mientras que el modelo es, a su vez, realmente real porque actuó como agente en esta elaboración, $y$, al ser conocido (pseudoinnovación del Sofista, ya que las Formas desde siempre fueron "conocidas": participio pasivo del verbo "conocer"), el modelo pathein.

En esta versión rejuvenecida de las Formas (que ahora adquieren la actividad —dynamis - que las libera de la anterior solemnidad estática), tanto ellas como lo individual-sensible existen realmente, y la única diferencia entre ambos universos reside en el carácter autónomo (y ya no "verdadero", ya que la verdad va a alojarse en el lógos) de las primeras, y en el estatus "dependiente" que caracteriza a sus copias.

$\mathrm{Y}$, en lo que se refiere al conocimiento como proceso, la Forma del Ser (idéa tou óntos, 254a) postulada en el Sofista confiere existencia tanto al objeto cognoscible (que debe estar en reposo) como al sujeto cognoscente (que lleva a cabo una actividad). La Forma del Ser, en cuanto "tercera realidad", no se confunde ni con el reposo ni con el movimiento, y sólo este fundamento (ahora) ontológico del carácter dinámico del alma del sujeto que conoce confirma el desideratum tantas veces expresado por Boeri: "para modificar nuestras creencias mediante un argumento, también necesitamos transformar nuestra propia disposición anímica" (p. 138).

La sección de Apariencia y realidad consagrada a Sócrates y a Platón concluye con una referencia al pasaje del Teeteto en el que se hace alusión, a propósito de Tales, al carácter "tonto y absurdo" del filósofo que vive entre dos mundos, imagen que se invierte cuando se trata de dar explicaciones argumentadas; en ese caso, "las personas que experimentan perplejidad son aquellas que antes se estaban riendo del filósofo" (p. 140). Y Boeri concluye: "Platón, claramente en mi opinión, parece estar disputando que cualquier persona, en algún momento de su vida, tendrá que enfrentar los asuntos aparentemente propios del filósofo" (pp. 140-141). En una obra anterior de Platón, el Parménides, el protagonista del diálogo (que no es otro que el Platón adulto que, bajo la apariencia de Parménides, aconseja al Platón joven, representado por Sócrates) se había adelantado ya al diagnóstico de Boeri cuando había aconsejado a Sócrates que, para llegar a ser un verdadero filósofo, debía dedicarse a esos ejercicios que la gente llama "charlatanería" (135d).

Recibido el 31 de julio de 2009; aceptado el 8 de septiembre de 2009. 